\title{
Evidence of a low-carbon tourism paradigm?
}

\author{
Author: \\ Susanne Becken (PhD) \\ Professor of Sustainable Tourism \\ Griffith Institute for Tourism (GIFT) \\ Griffith Business School, Griffith University, Gold Coast campus \\ Parklands Drive, QLD 4222 Australia \\ Phone: +61 (0) 755528827 \\ Email: s.becken@griffith.edu.au
}

Cite as: Becken, S. (2016). Evidence of a low-carbon tourism paradigm? Journal of Sustainable Tourism. DOI 10.1080/09669582.2016.1251446

\begin{abstract}
The global tourism industry has benefited from exceptional growth; however a number of challenges have the potential to seriously undermine the industry’s future aspirations. This research uses social representation theory to understand how the social group of tourism experts makes sense of the phenomena of 'tourism growth', 'low-carbon tourism', 'peak oil' and 'risks for tourism', and whether representations are indicative of different underlying paradigms. A total of 101 experts from various tourism professions and key demographics were interviewed using the free associations method. The findings reveal distinct representations of the four phenomena, but also significant linkages between them, in particular in relation to the global economy, transportation, energy supply and sustainability. Further, whilst experts appear grounded in the Dominant Social Paradigm of consumerism and neoliberal capitalism, there is evidence of alternative views that question some of the fundamental assumptions of the growth paradigm. In particular when asked about low-carbon tourism and peak oil, experts advanced associations that indicated an Alternative Paradigm. A broader paradigm shift originating from within tourism, however, alone is unlikely.
\end{abstract}


Keywords: Dominant Social Paradigm, Growth, Social Representation, Low-Carbon Tourism; Risks

\section{Introduction}

Tourism growth appears uncontested, and tourism forecasts assume continuous and maybe never-ending growth. However, growth may not eventuate as predicted. A number of risks have the potential to seriously undermine the tourism industry's aspirations. In fact, the Centre for Aviation (2013) recently stated that 'uncertainty is the new normal'. Uncertainty stems from a wide range of factors, including geopolitical developments in the Middle East, structural change in China, increasing fuel prices, changing consumer trends, climate change and natural disasters (Becken, 2015a). Uncertainty or fundamental changes in the system are rarely considered in tourism forecasts or future scenarios. The Tourism 2023 study from the United Kingdom (Draper et al., 2009) is an exception, because it specifically differentiated more certain trends (e.g. climate change impacts, water scarcity, cost of resources, growth in visitor numbers, an ageing population, and political instability) from those that were less certain (e.g. the impact of environmental attitudes and future legislation).

Conceptualising the future in a different way from the status quo might require a change in paradigm. At present and in the Western world the dominating paradigm is associated with economic growth, individualism, technological process and liberal democracies (Kilbourne \& Polonsky, 2005). The belief in a continuing expansion of tourism, facilitated by increasing incomes and technological advances, aligns well with the Western paradigm or the so-called Dominant Social Paradigm (DSP) (Pirages \& Ehrlich, 1974). The prevailing discourse tends to reinforce the DSP because, as a result of positive feedback loops, it creates those futures that are in line with the dominating paradigm. This was argued for the case of the Shell 
Scenarios whose strongly neoliberal discourse seemingly served the purpose of influencing the speculative markets that, in themselves, determine to a large extent the future of oil prices (Becken, 2011; Zalik, 2010). How framing and discourse shape the direction of activity was also noted by Nyberg and Wright (2015), who found that the performative way of constructing climate change as a market problem had real-world implications on how climate change will materialise and how it is going to be addressed.

In the tourism context it is conceivable that optimistic tourism forecasts and growth narratives trigger behaviours (e.g. investment) that will create exactly these futures as predicted. It is therefore not surprising that private and public sector actors continue to make their decisions in a 'predict and provide’ approach to planning (Goulden et al., 2014). Understanding how tourism stakeholders perceive the world and future directions of tourism, therefore necessitates the analysis of discourse, as the future only exists because of its linguistic construction (Schirmeister, 2014). Of course, not all stakeholders think or say the same, with different perspectives not only reflecting different levels of knowledge but also contrasting belief-systems that underpin how people see the world.

The belief-systems that influence how phenomena are perceived and talked about, sit alongside social institutions, norms, and habits - all of which are part of the underpinning paradigm that provides a lens through which people see the world (Milbrath, 1984). (Mass) tourism is part of the modern world and aligns comfortably within the DSP, although critical voices are becoming more prominent. Gössling et al. (2010), for example, pointed out that projected tourism growth is not compatible with climate change mitigation requirements, and Higgins-Desbiolles (2010) criticised the lack of equity in development arising from tourism. Importantly, discourse around tourism growth, climate change or sustainability is constructed collectively rather than by individuals. The theory of social representation (Moscovici, 1976, 
1980) therefore provides an appropriate framework for researching the perceptions of tourism stakeholders of key phenomena that shape the sector today and in the future.

Building on earlier research that examined tourism experts' social representations of peak oil (Becken, 2015b), this research explored four phenomena that are symptomatic of change and as a result may provide insights into whether tourism continues to be firmly anchored in the DSP or whether an alternative paradigm is emerging. The first phenomenon under investigation was the notion of "tourism growth", as it underpins one of the key elements of the DSP. As a possible (perceived) antithesis to growth, the concept of "low-carbon tourism" was explored, although it is understood that tourism growth and low-carbon forms of tourism may well work hand-in-hand - a notion that is indeed propagated by the industry (e.g. World Travel and Tourism Council, 2016). "Peak Oil” was included to see whether the implicit idea of resource scarcity and depletion provides an additional view to the 'low-carbon economy', or whether it reiterates points made in relation to low-carbon tourism. The final phenomenon to be examined was “future risks for tourism”. Adding a risk dimension was seen as important as it allows assessment of whether tourism stakeholders frame either growth or any of the other phenomenas as a risk or an opportunity. Including future risks therefore provides an additional angle from which the discourse about either growth of climate change might be discussed, given further important clues about underlying paradigms. In summary, this research asked tourism experts about their views on four inter-related, yet sufficiently distinct, phenomena. The responses helped to examine social representations and, ultimately the paradigms in which these are anchored. 


\section{Paradigms and social representations}

This section provides a review of the literature on social representations and how they relate to individual attitudes and beliefs on the one hand and socially shared paradigms on the other. A conceptual model of the embeddedness of intra-individual attitudes within broader representations, ideologies and paradigms is presented (Figure 1). The DSP and emerging alternative paradigms are explored in more detail.

\section{Figure 1 about here}

\section{Social representations}

Paradigms and ideologies are representations shared by members of a particular group or society (Vogel, 2009). At the same time, movements that challenge these, including the conceptualization of societal risks, emerge as a result of interactions between people and groups. So, rather than merely residing at the intra-personal level - understood as attitudes or risk perceptions - common representations evolve as a continuous negotiation between people’s information processing and their social, cultural and historical contexts (Joffe, 2003; Williams \& Baláž, 2015). This means, the way a particular object or idea is (socially) constructed cannot be separated from the individual and the contexts in which he or she operates. In other words, idiosyncratic attitudes held by individuals are nested within the broader social representations of the particular social group an individual belongs to (Anderson et al., 2013; Bidjari, 2011), and as Joffe (2003, p. 60) puts it "the 'we' becomes contained in the responses of the 'I'”'.

Social representations link the individual with society through collective meaning-making processes that lead to an emerging plurality of views and understanding amongst particular groups (Bauer \& Gaskell, 1999). Exploring these collective representations has been of particular interest in relation to new phenomena, contested issues or societal risks. A large 
number of studies within social psychology have used social representations theory to understand how complex social phenomena are interpreted by people in everyday life to make sense of scientific concepts and expert knowledge (Buijs et al., 2011). Topics investigated in earlier research range from mental illness, to diseases, biotechnology, environmental risks (e.g. climate change) and energy sources (Bauer \& Gaskell 2002; Becken, 2014; Gangl et al., 2012; Joffe, 2003; Moloney et al., 2014). Social representations constitute a hybrid form of both scientific and life world knowledge (Bauer \& Gaskell, 1999). They are important because they represent shared notions, ideas and images (O’Neill, 2013) or in short lay knowledge (Buijs et al., 2011). Social representations are not to be seen as 'incorrect' versions of scientific understandings, but rather they reflect how the public sees complex issues, and to this extent they represent 'reality' possibly more so than the scientific knowledge per se (Bauer \& Gaskell, 2008).

As discussed in Becken (2015b), the emergence of a social representation involves processes of anchoring and objectification (Wagner \& Hayes, 2005). Anchoring involves the assimilation of new ideas and concepts by linking them with existing 'templates'. By doing so, it makes new events more familiar and concrete, and diminishes potentially threating aspects of the new phenomena (Bidjari, 2011; Joffe, 2003). As such social representations are a way of coping and problem solving (Moscovici, 1976). This dynamic and evolving process, once again highlights, the importance of understanding historical and social contexts, as well as affective dimensions, rather than purely cognitive information processing (Bauer \& Gaskell, 1999). In conjunction with anchoring, which mainly draws on familiar ideas from the past, objectification helps to turn a new representation into a "short hand" that helps people to make immediate sense of a phenomenon in social interactions (Tsoukalas, 2006). For example, Becken (2015b) found that a sub-group of tourism professionals objectified the notion of peak oil by "saturating it” (Joffe, 2003, p. 64) with the images of sustainability. The 
media often play an important role in objectifying new ideas, for example by providing powerful images or using well established metaphors and symbols. Dolly the sheep, for example, became a well-known object of a particular social representation of biotechnology (Bauer \& Gaskell, 2002).

Social representations are part of larger meaning systems and representations can merge, interact or contrast with each other. In addition, different and potentially conflicting modes of thinking (Moscovici, 1976) can co-exist both at the individual and social levels. This so-called polyphasia indicates that people do not necessarily strive for global cognitive consistency, but apply representations and rationalities to a particular context or situation (or stimuli) as they seem fit (Jovchelovitch, 2002). Being aware of different social representations makes it easier for people to makes sense or negotiate meanings in different situations and social groups (Brondi et al., 2014). How social representations of related phenomena interact has not explicitly been researched (Sarrica \& Wachelke, 2010), but is likely to relate to the above-mentioned processes of anchoring and objectification. Overlapping representations are possibly linked to a common under-lying ideology (Bidjari, 2011) and paradigm (Vogel, 2009) (Figure 1). This research is the first to explore tourism experts' representation of key tourism phenomena related to growth, climate change, peak oil and risks.

\section{Socially dominating paradigm versus alternative paradigm}

Modern (mass) tourism is largely a phenomenon of the developed world. It is fuelled by increasing disposable incomes and the freedom to discover. Tourism and global mobility do not exist in isolation, but are part of a global system in which support for neoliberal growth dominates (for an analysis of tourism mobility see Higham et al., 2014; Young et al., 2014). Socio-economic systems and the representations within them can be understood by analysing prevailing paradigms. The concept of a paradigm builds on Kuhn’s (1970) early conceptualisation of a scientific paradigm as widely accepted and tested ways of solving a 
particular type of problem. In 1974, Pirages and Ehrlich developed the idea of a paradigm further and coined the term Dominant Social Paradigm (DSP). The DSP refers to the norms, beliefs and values that dominate within a culture or a social group. Importantly, it is not necessarily the values that dominate in terms of numbers, but those held by elites and leaders who constitute the paradigm to legitimise their influence and power (Kilbourne, 2009). The belief systems in a paradigm that have behavioural implications for particular social groups are best described as ideologies. Vogel (2009) concluded that ideologies are inherent in paradigms and represent the link between the "non-observable and ideal part of an institutional order" and its "rule-based practices” (p. 94).

Subsequently, several researchers have sought to understand and define the DSP of the Western world. Commonly identified dimensions relate to the notions of material abundance, perpetual economic growth, and strong belief in technology. These align strongly with anthropocentric world views and a consumerist culture (Gorge et al., 2015). Kilbourne, Beckmann and Thelen (2002) decomposed the structure of the DSP into three key dimensions, namely technology, politics and economics. Technologically, the DSP is shaped by an optimistic attitude towards technology as a fix for most problems and boundaries of human endeavour. Often this manifests in large-scale and centralised technologies that are controlled by few. Liberal democracy, coupled with extensive private property rights and limited government intervention is the preferred political system of the DSP, cumulating in a freedom - if not expectation - to consume. As a result, the economic dimension of the DSP centres around free markets and economic self-interest as the main motivator of decision making (Kilbourne et al., 2002). The private-sector focused tourism paradigm (HigginsDesbiolles, 2010) is firmly embedded within the broader DSP.

As argued by Kuhn (1970), paradigm shifts occur when the existing paradigm fails to provide solutions to increasingly challenging problems and when a growing number of members in a 
group have lost faith in the existing paradigm. Gorge et al. (2015) point out, for example, that questions around environmental behaviour and social justice remain unanswered and are in contrast to most other systemic imperatives, incentives and rhetoric prescribed through the DSP. As a result, and as an antithesis to the dominant paradigm, alternative paradigms emerge (see Cotgrove’s (1982) contrasting framework of the "Dominant Paradigm" and an "Alternative Ecological Paradigm" in Olsen et al., 1992). Alternative paradigms are not easy to define, other than that they evolve as a response to dominating paradigms. Sometimes a proclaimed alternative paradigm may only constitute a marginal variation to the dominant paradigm as as a result does not offer the opportunity of a paradigm shift. An early example of an alternative paradigm is the New Environmental Paradigm by Dunlap and van Liere (1978), which developed in the 1960s and 1970s in response to growing environmental concern and following Rachel Carson’s book Silent Spring (Anderson, 2012). Dunlap and van Liere researched the public's views on potentially polarising aspects of the DSP, in particular to ecologically incompatible behaviours, and sought to uncover diverging systems of belief. The NEP opposed the fundamental beliefs of the DSP - or the 'Human Exceptionalism Paradigm' - that assume that humans are unique creatures that do not face boundaries on planet Earth (Catton \& Dunlap, 1978). The NEP-scale to measure opposing beliefs (e.g. anthropocentric versus biocentric) is still frequently used to assess people’s alignment with an environmentally anchored paradigm.

Thus, alternative paradigms evolve through those who express concern with the DSP at a given time its socio-ecological implications (Kilbourne et al., 2002). Alternative paradigms of recent times resonate with notions of 'limits to growth' (Meadows et al., 1974), steadystate economy (Daly, 1978), technology scepticism (Huesemann \& Huesemann, 2011), and social equity (Higgins-Desbiolles, 2010). Authors as early as Boulding (1966) in his seminal paper on ‘cowboys’ and ‘spaceship Earth’ or more recently Heinberg (2011) have examined 
the nature of economic and financial principles and systems and unravelled why, in their view, economic theories are flawed to the extent that a long-term continuation of current patterns is physically impossible. One major flaw is the disregard of physical laws. In response to undeniable physical constraints, the principle of 'sufficiency' has been advanced as an antidote to the DSP as it deliberately seeks to downsize consumption to levels that reflect needs rather than desires (Gorge et al., 2015).

Sufficiency - and implications for current industries - is particular pertinent in the tourism context, since most travel is to be seen as a discretionary (and hedonistic) activity rather than an existential need (Higgins-Desbiolles, 2010). A related notion, ‘de-growth’, is propagated by more radical movements, including so-called 'peakists', comprising people who are highly concerned about a peaking of global oil production. To protect themselves from apocalyptic futures of economic collapse, resource wars and social conflict, peak oil-concerned choose alternative (sometimes hermitic) localised lifestyles with parallel systems to mainstream economies (Becken, 2015a). Clearly, a wide range of perspectives and social groups question the DSP, or parts thereof, but as argued by Alexander (2014) the current fragmentation into 'radical reformists', ‘eco-socialists', and 'eco-anarchists' impedes the development of a coherent and strong alternative paradigm.

Building on Ecological Modernisation Theory, a suite of green (political) economy models have been advanced with various degrees of emphasis on resource efficiency, low carbon development, innovation and partnerships, market-based mechanisms and social inclusion (Barry, 2007; Bailey \& Caprotti, 2014). The mainstream tourism debate has readily picked up on the concept of a Green Economy (e.g. World Economic Forum, 2009), evidenced amongst others in UNEP and UNWTO’s (2012) background report on tourism in the Green Economy and academic analyses, such as Law et al.'s use of the Green Economy framework for tourism planning in Bali. Ecological Modernisation in general, and Green Economy in 
particular, have been criticised for not providing a sufficiently radical shift from the current paradigm, and merely reinforcing existing structures and elites through "reform(ulat)ed capitalism” (Bailey \& Caprotti, 2014, p. 1802), without addressing the root causes of unsustainable development. In fact, one might argue that the notion of sustainable development and the new Sustainable Development Goals, whilst aiming to improve social and environmental conditions are still firmly anchored in the DSP. A full examination of sustainability as a paradigm goes beyond the scope of this paper. In the face of potential 'smoke-screens' and in an attempt to radicalise Ecological Modernisation (Barry, 2007) and allow for discourse that effectively challenges the growth paradigm, the concept of postgrowth development has emerged. 'Post-growth economics' as an alternative paradigm provides one possible frame to address some of the pressing questions, including changes to the current finance system, implications of carbon budgets, radical lifestyle implications, transition pathways, and population growth (Alexander, 2014).

In the tourism arena, critical examinations of the DSP remain scant. Previous research has pointed to some of the challenges inherent in the DSP, for example, Hinch (2008) observed that the underpinning values of the DSP are not particularly suited to support selfdetermination by indigenous people in the context of tourism development and management. Further, calls for decarbonising tourism (Becken, 2015a; Gössling et al., 2010) and promoting new forms of tourism, such as ‘slow tourism’ (Dickinson \& Lumsdon, 2010) indicate that alternative paradigms might be required to facilitate transformation to fundamentally different forms of tourism that can be viable in a post-growth framework. Moving beyond current emphasis on technological improvements (Gössling et al., 2010) to include behavioural change is a critical step. To date, however, tourism research has not explored the current discourse and social representations of tourism growth, low-carbon tourism, peak oil and future risks and how these relate to underlying paradigms. 


\section{Methodology}

The representations of four phenomena have been explored using a word association task that elicits spontaneous connotations that interviewees have when being confronted with a particular term. The 'free association method' was suitable for this present research because it enabled the researcher to extract top-of-mind 'meanings' from sector leaders, rather than prefabricated templates that generate standard (and sanitised) answers.

\section{Sample - tourism elites}

Tourism experts in leadership roles were selected, following recommendations by Parker et al. (2013) that leadership elites are more likely to address environmental challenges and effectively achieve outcomes. Thus, the target population for this research was leading tourism academics, consultants, managers, directors and chief executive officers from Government and Industry. Recruitment of research participants was mainly through the personal networks of the author and two research assistants. The aim was to interview a broad group of experts to cover a range of sector sub-groups, nationalities, age groups and gender. In addition to the personal networks, major conferences (academic and industry) were used as a vehicle to approach and interview tourism leaders. Potential interviewees were identified from the speakers list and contacted beforehand to arrange for a meeting time (Becken, 2015b).

The final sample included 101 experts from a wide range of backgrounds and countries (Table 1) who were interviewed between October 2013 and August 2014 (Becken, 2015b). Interviewees were asked to participate in a 'blitz interview on the future of tourism' (taking on average 5 minutes). Fifty-eight interviews used skype or the telephone with the remainder 43 interviews having been undertaken face-to-face. The association task involved the following four terms: ‘future risks for tourism', ‘tourism growth’, 'low-carbon tourism' and 
'peak oil'. To test possible associative effects (i.e. that participants think of growth/carbon/oil as risks when asked about future risks as the last phenomena), the order of questions was manipulated: 53 experts were asked in the order with risk first, and 48 were invited to provide their personal associations on 'tourism growth', 'low-carbon tourism' and 'peak oil', before responding to 'risks'. Regardless of the order, participants were asked to provide up to five words or phrases describing their spontaneous association with each of the four terms.

\section{Table 1 about here}

\section{Analysis}

As described in Becken (2015b) for the term 'peak oil', the analysis involved coding of the associations and grouping them into categories. In total, there were 477 associations for 'tourism growth', 486 for 'low-carbon tourism', 480 for 'peak oil' and 485 for 'future risks'. The coding process was iterative and the scheme was revised several times to adequately capture responses in meaningful codes (Anderson et al., 2013). The process first involved open coding to create 'labels' (e.g. 'emerging markets'), followed by axial coding where the initial codes were grouped into higher-order themes (Saldana, 2013). Coding was undertaken manually (i.e. in an excel spreadsheet), which was deemed appropriate since the answers provided by respondents were either single words or very short sentences. In fact, in some sentences the word association was directly used as the primary code (e.g. 'China' as an association to the phenomenon of tourism growth). The author coded all associations herself to ensure consistency, but undertook the process twice (with a break of 2 months in-between) to confirm that the codes were stable.

Codes were developed to capture cognitive as well as normative or emotional associations (Buijs et al.; 2011, Fischer et al., 2012). The earlier in-depth analysis (Becken, 2015b) 
included respondents' images associated with peak oil (i.e. participants were asked to provide a mental image or photograph-type association with peak oil). The findings then revealed that these images tended to be much more emotional than the word associations. For example they often conjured apocalyptic scenes (e.g. war and fighting, a plane crashing) or, on the other hand, peaceful sceneries with 'happy people'. Since this present analysis only includes word associations, it is likely that most codes reflect cognitive aspects of the representations.

To explore the structure of social representations into their relatively stable core and a changeable periphery (Ernst-Vintila, 2011), a proto-typicality analysis was undertaken (Vergès, 1992). The ranking provides a sense of the prominence of a particular association. Frequencies were obtained by summing the occurrence of a code across all five association for reach respondent, and then across all 101 interviewees. The ranking was derived by weighting the first mention with a factor of 5 , the second mention with a factor of 4 , the third mention a factor of 3 , up until to the $5^{\text {th }}$ mention with a weight of 1 . Each code was then displayed visually on a matrix with two dimensions (frequency and rank) to identify those codes that are both frequent and 'top-of-mind' and therefore constitute elements of the central core of a representation (Wagner et al., 1996). In addition to the core, the so-called contrast zone (i.e. the top left quadrant) is of interest as it represents associations that are forefront, but for a smaller number of respondents.

Following Parker et al. (2013) the presence of a potential shift away from the DSP was examined. The associations with the four concepts were coded to capture whether a respondent aligned with the DSP or indicated correspondence with an alternative paradigm. To this end, each respondent's five associations for each concept were assessed. For example, in relation to the concept of 'tourism growth', the five associations provided by a male consultant from Australia were: 'increasing numbers of tourists', 'increasing yield', 'investment', 'increasing incomes', and 'management'. These indicate broad agreement 
with the DSP and were therefore coded as 'DSP'. In contrast, the growth associations by a male consultant from The Gambia were 'development for people, 'protection of environment', 'tourist awareness', 'responsible marketing, and 'rights of people protected'. These indicate a level of awareness of challenges within the current system, and were therefore coded as 'AP'. Several respondents provided a set of associations that were ambiguous, for example pointing at tourism's impacts on the environment on the one hand and economic benefits for communities on the other. These were coded as 'ambivalent'. A small number of respondents provided associations that did not clearly reflect any underlying values or beliefs, and these were coded as neutral. Because of the challenges inherent in collapsing five associations into an assumed underlying paradigm, the coding process was repeated after a period of four weeks. The intra-coder reliability was between $61 \%$ and $80 \%$ for the four phenomena. Only those respondents who were coded consistently in both phases were included in the analysis.

\section{Limitations}

This research has several limitations, beginning with the selection of tourism experts who participated in this research. While care was taken to select a broad range of 'elite' representatives, it is possible that there is an inherent bias due to the researchers' networks, and the resulting snow-balling approach. Further, some countries are represented more strongly than others and a truly global perspective has not been achieved. Methodologically, social representation theory has been criticized as broad (Gangl et al., 2012) and analytically challenging (Dickinson et al., 2009). Whilst the free association technique has been used previously, it remains problematic to sample what individuals think and defer what their social context is that influences this thinking (Joffe, 2003). Finally, the coding process is subject to the researcher's own interpretations, values and beliefs and as such not free of bias. As indicated above, the coding of associations into underlying paradigms has been 
challenging and results are indicative only. Further in-depth research through interviews with tourism leaders are recommended to explore the notion and nature of an emerging alternative paradigm.

\section{Results}

The social representations of the four phenomena under investigation are examined first, followed by an analysis of how responses might reflect either the DSP or an alternative paradigm.

\section{Social representations}

Tourism experts' associations with ‘tourism growth’ were scattered, and only two associations, namely the 'Importance' of tourism growth and 'Industry challenges' constituted the core representation in the top right quadrant (Figure 2). Examples of industry challenges included a lack of investment, infrastructure constraints, and low yield tourism highlighting particular barriers to the economic growth of tourism. The most frequent association, although not top-of-mind, was around 'Questioning growth', for example "current extrapolations are not realistic" (male industry, Australia), or "purpose of growth" (male academic, UK). 'Emerging markets’ was the highest ranking association, often with reference to China. In the contrast zone (top left quadrant), questions were raised around ‘Carrying capacity’, 'Uneven’ growth, and environmental problems (including climate change), indicating recognition of major problems associated with growth.

Figure 2 here

The core of the social representation of 'low-carbon tourism' was strongly influenced by transport associations, as well as statements that expressed cynicism (often choosing 
emotional exclamations, such as “Goodness!" or "Phraseology”) or lack of understanding of what low-carbon tourism means (Figure 3). For example, a large number of tourism experts ( $N=40$ associations) felt that low-carbon tourism is “extremely challenging” (male industry, UK), “difficult to implement” (female consultant, UK) and “unrealistic” (female academic, Australia). Others were outright labelled low-carbon tourism as a "pipe dream” (male academic, UK) and “hypocritical” (male consultant, NZ). Notwithstanding, tourism experts expressed support for the notion of low-carbon tourism, evident in the codes 'Important' and 'Supportive', which both ranked highly. Interestingly, changing 'Behaviour’ was more frequently mentioned than specific ‘Technology’. A female academic from Australia noted "getting people to reduce activities that cause carbon" and a male industry representative from Spain suggested "the dominance of new patterns".

\section{Figure 3 here}

The social representation of peak oil, similar to the one of low-carbon tourism, contained a mix of factual associations (e.g. related to alternative energy sources) and value-laden (and emotional) statements that either confirmed the urgency to address peak oil (coded as 'Affirmative'), questioned the concept ('Controversial'), or indicated the need to know more (“most people would have no clue what it is or how far away it is", female academic, Australia). 'Alternative energy’ featured highly and, similar to low-carbon tourism, transport was identified as an important element of the peak oil representation (Figure 4).

Figure 4 here

To see whether tourism growth or carbon-related challenges are seen as a risk, respondents were also asked about their associations to 'future risks'. The most frequent and highly ranked associations with the 'future risks for tourism' related to 'Safety', the 'Economy' and 
‘Climate change’ (Figure 5). Associating safety with risk is not surprising, but the role of economy as a risk was more complex. Whilst some saw the risk in a continuously weak global economy since the Global Financial Crisis (i.e. not supporting desired growth), ohers felt that it is the growth in itself that poses the risk, for example as a result of crowding, congestion and over-use of resources. 'Massification' of tourism was mentioned so often that it was coded separately, as well as the environmental and social 'Destruction' of tourist destinations. A male industry representative from Hungary, for example, saw the "loss of the attraction itself' as a key risk for tourism. 'Resources' and 'Energy constraints', natural 'Disasters' and 'Pandemics' were also put forward as important risks that were top-of-mind. All of these are in the contrast zone of high ranking (i.e. the top left quadrant), but have relatively lower frequencies. Responses to the ‘future risks for tourism’ phenomenon did not differ significantly depending on the order in which phenomena were presented to participants (i.e. risks mentioned first or last). That means that the risk of an associative effect depending on order did not materialise.

Figure 5 here

\section{Underlying paradigms}

A comparison of the codes shows substantial overlap between the four social representations, although it appeared that notions of growth, low-carbon tourism and peak oil tend to be more emotional issues than talking about risks, which triggered more factual associations. Many of the identified risks related directly to the other three phenomena, highlighting the degree to which the representations are interlinked. All representations contained evidence of a move towards 'sustainability thinking'. In particular, the global economy, transport systems and energy supply emerged as linking elements relevant to all four phenomena. Associations that 
reflected challenges or opportunities endogenous to the tourism sector (e.g. changing consumer preferences) shaped the social representations of risks, growth and low-carbon tourism, but not the one related to peak oil, indicating that peak oil is largely understood as a phenomenon external to tourism.

The four phenomena were juxtaposed based on four key dimensions of the DSP (see also Kilbourne et al., 2002, 2002), namely economic growth, material abundance, technology, and politics (Table 2). The importance of a strong economy, as a key ingredient of the DSP, was reflected in associations made in relation to 'tourism growth' and 'future risks', with a simultaneously existing high level of criticality and questioning of the need and nature of growth (Alexander, 2012). The peak oil representation related to economic growth through a perceived vulnerability of the global economy (and tourism within it) to rising oil prices or shortages.

\section{Table 2 here}

In terms of natural resource abundance, all four social representations contained references to finite energy sources and the need to develop alternatives - indicating scepticism of a world of infinitely available resources (therefore questioning one of the fundamental assumptions of the DSP). Experts' framing of resource challenges differed slightly, with associations for 'tourism growth' and 'risks' focusing more on the constraints (e.g. “water and energy availability”, “limited resources”) and associations for 'low-carbon tourism' and 'peak oil' indicating solutions (e.g. "alternative energies become critical”, "biofuels”, “cleaner energy”). Associations of alternative energy sources (both renewable and non-conventional fossil fuels) often related to new technologies and the belief that these will address future shortfalls. Apart from new energy technologies, technological advances were mainly seen in 
relation to transportation. This technology belief sits well with the traditional thinking of the DSP, and interestingly the role of technology was not apparent in the presentation of future risks to tourism. Asking respondents specifically about low-carbon tourism and peak oil, however, triggered solution-oriented associations (e.g. public transport systems, walking and biking) that align better with an alternative paradigm and went beyond technological approaches. These findings indicate that the framing shapes the avenue of thought pattern that might follow, to the extent that associations reflect quite different paradigms, often for the same respondent (see below).

Several experts saw a major risk for tourism in the lack of tourism planning and policymaking (e.g. “unmanaged growth”, “short-termism”, and "lack of public sector support for tourism”). The fear of conflict was evident in both the 'tourism growth' and 'risk' representations. Not surprisingly, the social representations of low-carbon tourism and peak oil contained reference to climate change mitigation policies, the need to prepare for the future and strong leadership.

The coding of tourism experts' associations into a paradigm revealed that the representation of ‘tourism growth' largely reflected the DSP paradigm (Figure 6). For example, tourism experts put forward ideas about airline capacity growth, cruise ship tourism, outer space travel, new markets and products, and expanding into new destinations. Some expressed feelings, for example that tourism growth makes them feel "excited" (female industry, Australia) and others thought of "latest technology" and "investment” (male consultant, Switzerland). When thinking about growth, only 15 participants associated terms that unambiguously indicated an underlying alternative paradigm (e.g. "inequitable”, “unbalanced" and "selfish”, male academic, UK). In contrast, the other three phenomena evoked more associations that indicated critical views of the DSP. Respondents who were coded as proponents of an alternative paradigm on the respective phenomena, put forward 
associations around finite resources, a rethinking of lifestyles, new governance systems, quality over quantity, social equity, and localised tourism (including 'staycation'). Out of the 101 tourism experts, 55 displayed relative consistency in their (coded) underlying paradigm across the different phenomena, with at least two out of three (or three out of four, if all were available) codes for the four phenomena being the same. For the other 46 participants, there was a level of inconsistency (e.g. providing DSP-aligned associations for 'growth', but then indicating criticism and existence of alternative belief systems for any of the other phenomena).

Figure 6 here

\section{Discussion}

This research interviewed 101 tourism experts using the free association method to elicit evocations of 'tourism growth', 'low-carbon tourism', 'peak oil', and 'future risks for tourism'. Understanding possible future pathways for tourism inevitably rests in the analysis of what people think or believe today, as the future is always a product of what has been put in place in the present. As such, analyzing tourism leaders' present views on key phenomena provides useful insights into potential futures, even though Schirmeister (2014) warn that such analyses of discourse are not a magic crystal ball but require transparent interpretation. To understand how the social group of tourism experts makes sense of and creates meaning for the four phenomena, social representation theory was used as a theoretical lens (Joffe, 2003). Following Vergès (1992) and other researchers in this field, an analysis of frequency and ranking revealed those elements that are at the core of a social representation (i.e. mentioned often and early) and those that are typically mentioned early, but less frequent in 
total. It is these latter associations in the 'contrast zone', that are of particular interest, as they embody ideas that indicate shifts of, or challenge the existing social presentation (Sarrica \& Wachelke, 2010).

The social representation of 'future risks for tourism' was examined to obtain a generic insight into how tourism experts see the future, and whether any of the challenges implied in the other three phenomena were identified as risks. The findings showed that, indeed, risk associations reflected anticipated problems related to growth, energy availability and climate change. When asked directly about the other three phenomena, social representations clearly indicated contested space. The associations relating to growth, low-carbon tourism and peak oil highlighted that people were often either openly dismissive or supportive, indicating the existence of emotive views that reflected polarized underlying values and belief systems.

The research identified considerable overlap between the four representations. This is perhaps not surprising. The Adaptive Control of Thought Theory (Anderson, 1983) suggests that memories consist of actual facts and networks of associations that can be stimulated to retrieve information. A stimulus could be a situation, a word, a picture or even a smell. In this research, the stimulus or cue was a verbalized phenomenon, which once presented to the respondent would have activated a link in the memory to other nodes and stored information. Nodes that are more active, or have recently been stimulated (e.g. prevalent discussions about Chinese tourism), are more likely to be activated. This process is similar to the effects in a semantic network (e.g. similar words) or in associative models (e.g. a frequent co-occurrence of items). Thus associations put forward by tourism experts in relation to one phenomenon may have triggered particular associations related to the other phenomena. A possible associative effect was tested by changing the order in which phenomena were presented ('future risks' first versus last), however, no measurable effect was observed. Rather than being subconsciously associative it is more plausible that the representations, indeed, inter- 
relate, anchored in the common denominators of the global economic system, energy supply, transportation systems for tourism and sustainability.

A comparison of social representations showed the relative similarity between 'future risks for tourism' and 'tourism growth' on the one hand, and the two other phenomena on the other hand (Table 2). Both representations contained positive associations that highlighted the importance of growth and a thriving global economy; however, the representations also comprised paradigm-challenging notions of limits to growth, massification and commodification of tourism, environmental and cultural destruction, and social inequity. In particular, low-carbon tourism and peak oil triggered thoughts of (adapting to) change, transition and in some cases transformation. Experts were better able to consider pathways to achieve low-carbon tourism than addressing peak oil, which was more often considered an industry-external issue that calls for technological solutions. The much advanced public and academic discourse on tourism and climate change, including carbon footprinting and management, might explain these findings (Becken, 2014; Miller et al., 2010; Young et al., 2015).

Examining social representations of key issues is useful to understand how tourism experts make sense of complex phenomena, but as noted by Kilbourne and Polonsky (2005), analyses are incomplete if underlying paradigms remain ignored. The examination of experts’ associations in relation to the DSP clearly reveals how the core dimensions of economic growth, material abundance, technological solutions and politics (and policy) are reflected in the tourism context. However, the social representations elicited in this research also indicated the existence or emergence of an alternative underlying paradigm; one that questions growth and points to resource constraints and social inequality. This became apparent across all four phenomena. In particular, when a phenomenon was framed in a nonorthodox way (e.g. ‘low-carbon tourism’ rather than ‘tourism growth’), experts revealed 
views alternative to the neoliberal growth paradigm or the DSP. Whilst the majority of respondents showed relative consistency in their underlying paradigm, experts also displayed conflicting associations. Thus, just as observed at the intra-individual level through cognitive dissonance (Festinger, 1957) and the social-representation level through polyphasia, paradigms may exist - and shape people’s cognitions - in parallel and in conflict, depending on the context or framing of a particular issue.

It is not uncommon, that challenges to the dominant paradigm are reconciled in the wider discourse using the underpinning logic of the existing paradigm (Kilbourne, 2009). In the case of the DSP constraints to growth are addressed through innovation and technological solutions. Tourism experts were particularly inclined to identify technological solutions in relation to the peak oil problem, for example by suggesting the exploitation of nonconventional oil resources (Becken, 2014). In addition, the role of advanced transport technologies and systems was highlighted across all four phenomena. Techno-belief was often accompanied by faith in market-based mechanisms, including emission trading schemes or carbon taxes that facilitate the development of low-carbon tourism as part of a 'carbon economy’ (Bailey \& Wilson, 2009). The neoliberal technocentrism and managerialism reflects weak ecological modernisation approaches (Bailey \& Caprotti, 2014), although this research uncovered the emergence of behavioural change patterns (e.g. in the low-carbon representation: travel less and more locally) that would both enhance the effectiveness of mainstream measures and challenge the consumerist aspects of the paradigm.

Inadequate policy making and a sense that tourism is insufficiently understood were identified as risks and barriers to achieve (sustainable) growth. Questions around responsibility, leadership, and conflict emerged across all four representations, indicating some awareness of governance challenges associated with the DSP. As observed by Hall (2013), however, a 'lock in’ into neoliberal values makes it unlikely that experts’ alternative 
views instigate a paradigm shifts. In the case of Chilean elites, Parker et al. (2013) found that even those leaders who engaged in AP discourse, showed little evidence of actively supporting change towards a new paradigm. In fact, the researchers concluded that the local elites will not change political and economic structures to address climate change unless a global political framework will force them to do so. In fact, changing the DSP is not in the interest or mandate of current policy makers (Kilbourne \& Polonsky, 2005), with the selfenforcing dimensions of paradigms (including the ideology) ensuring that the elites remain in power. Catalysing fundamental change, for example through constructing a new ideology, is particularly challenging when the existing ideology is not deconstructed at the same time (Vogel, 2009). In addition, Young et al. (2015, p. 12-13) remind us that the "task of imagining alternative futures free from the ideological contexts that produce these futures as their cultural expressions” is almost impossible.

The concept of a Green Economy, promoted as a new paradigm by key international organisations may not deliver the needed transformations required in an increasingly resource-constrained world (Alexander, 2014). In fact, the Green Economy (or the carbon economy, Bailey \& Wilson, 2009) merely presents a 'nudge’ (Hall, 2013) and distracts from more fundamental changes. Nudging through the provision of small incentives or particular choice sets has become an important tool of Government policy (Goulden et al., 2014). Proposed choices comply comfortably with economic structures, institutions and core values and deliver short term benefits (e.g. conceptualising climate change as a market risk, see Nyberg \& Wright, 2015), but fail to address underlying root problem. It therefore unclear whether emerging scepticism of the DSP, as evident amongst tourism leaders in this research, will contribute to a paradigm shift, or whether current movements of low-carbon tourism merely represent first and second-order changes and fall short of third order changes that shift ideologies and paradigms (on the order of changes see Hall, 1993, in Bailey \&Wilson, 2009). 
Regardless, and in the meantime, conflicting policies and apparent paradoxes are leading to social discontent and cynicism, as clearly observed in experts’ responses to low-carbon tourism and to some extent peak oil. As argued in the context of carbon-neutral land transport targets in the United Kingdom, the general public are not oblivious to mixed messages and often respond with scepticism or inaction as a result (Goulden et al., 2014; Bailey \& Caprotti, 2014). Contradictory policies around decarbonisation on the one hand and economic growth (including airport expansions) on the other are undermining the credibility of change policies, and signal reluctance to evolve or transform from the DSP into an AP. Clearly, at this point tourism planning occurs in the context of the DSP and limited research has explored how the current structures and interests, and underpinning values influence policy making and planning (Dredge \& Jamal, 2015). Alternative paradigm discourse remains at the margins and is not incorporated into mainstream planning, despite the emergence of a DSP-critical sentiment.

\section{Conclusion}

Using social representation theory in combination with the free association technique, this research explored how tourism experts perceived four different, but inter-related phenomena. Whilst providing insights into the specific elements of the four representations, this research highlighted the linkages between the four phenomena, in particular around the dimensions of the global economy, transportation, energy supply and sustainability. Participants revealed broad consistency with the Dominant Social Paradigm, in particular when asked about ‘tourism growth', but also indicated awareness and importance of alternative paradigms that question some of the dominating neoliberal values and assumptions. When framed in the context of 'low carbon tourism' and 'peak oil' experts generated more solution-oriented representations, compared with those related to 'risks for tourism' and 'tourism growth'. 
Contrasting representations and underlying paradigms were evident within individuals, indicating the co-existence (or polyphasia) of different values and beliefs depending on context and specific aspect of the future. Whether the emerging awareness of, and agreement with an alternative, low-carbon paradigm will result in a paradigm shift remains to be seen and is unlikely to be within the control of tourism stakeholders themselves.

\section{References}

Alexander, S. (2014). Post-growth economics: a paradigm shift in progress. Arena Journal, 41/42, 93-122.

Anderson, J. R. (1983). The Architecture of Cognition. Cambridge, MA: Harvard University Press.

Anderson, M.W. (2012). New Ecological Paradigm (NEP) Scale. Pp. 260- . The Berkshire Encyclopedia of Sustainability: measurements, indicators, and research methods for sustainability. Berkshire Publishing Group. Available (02/08/16) Anderson, M. (2012). New Ecological Paradigm (NEP) Scale. Berkshire Publishing Group. Retrieved from: http://umaine.edu/soe/files/2009/06/NewEcologicalParadigmNEPScale1.pdf

Anderson, N.M., Williams, K.J.H. \& Ford, R.M. (2013). Community perceptions of plantation forestry: the association between place meanings and social representations of a contentious rural land use. Journal of Environmental Psychology, 34, 121-136.

Bailey, I. \& Caprotti, F. (2014). The green economy: functional domains and theoretical directions of enquiry. Environment and Planning A, 46, 1797-1813. 
Bailey, I. \& Wilson, G.A. (2009). Theorising transitional pathways in response to climate chane: technocentrism, ecocentrism, and the carbon economy. Environment and Planning A, 41, 2324-2341.

Barry, J. (2007). Towards a model of green political economy: from ecological modernisation to economic security. International Journal of Green Economics, 1(3/4), 446-464/

Bauer, M \& Gaskell, G. (2008). Social representations theory: a progressive research programme for social psychology. Journal for the Theory of Social Behaviour, 38 (4). 335-353.

Bauer, M. \& Gaskell, G. (1999). Towards a paradigm for research on social representations. Journal for the Theory of Social Behaviour, 29(2), 163-186.

Bauer, M. W. \& Gaskell, G. (eds) (2002). Biotechnology: the making of a global controversy. Cambridge University Press, Cambridge, UK.

Becken, S. (2011). A Critical Review of Tourism and Oil. Annals of Tourism Research, 38(2), 359-379.

Becken, S. (2014). Oil depletion or a market problem? A Framing Analysis of 'Peak oil in The Economist News Magazine. Energy Research and Social Science, 2, 125-134.

Becken, S. (2015a). Peak oil - Peak Travel? The future of tourism in an oil-constrained world. Cleveland: Channel View Publications.

Becken, S. (2015b). Peak Oil - a hidden issue: social representations of professional tourism perspectives. Journal of Sustainable Tourism. Doi: 10.1080/09669582.2015.1042484 
Bidjari, A.F. (2011). Attitude and Social Representation. Procedia- Social and Behavioural Sciences, 30, 1593-1597.

Boulding, K.E. (1966). The Economics of the Coming Spaceship Earth. Available (14/10/16) http://www.ub.edu/prometheus21/articulos/obsprometheus/BOULDING.pdf

Brondi, S., Armenti, A., Cottone, P., \& Mazzara, B. (2014). Parliamentary and press discourses on sustainable energy in Italy: No more hard paths, not yet soft paths. Energy Research \& Social Science, 2, 38-48.

Buijs, A.E., Arts, B.J.M., Elands, B.H.M., \& Lengkee, J. (2011). Beyond environmental frames: The social representation and cultural resonance of nature in conflicts over a Dutch woodland. Geoforum, 42, 329-341.

Catton, W.R. \& Dunlap, R.E. (1978). Environmental Sociology: A New Paradigm. The American Sociologist, 13, 41-19.

Centre for Aviation (2013). World Aviation Yearbook 2013: Global overview. Available (01/11/13) http://centreforaviation.com/reports/

Cotgrove, S. (1982). Catastrophe or Cornucopia. Chichester: Wiley.

Daly, H.E. (1978). On Thinking About Energy in the Future. Natural Resources Forum, 3(1), $19-26$.

Dickinson, J. \& Lumsdon, L. (2010). Slow Travel and Tourism. London, Washington: Earthscan.

Dickinson, J.E., Robbins, D., \& Fletcher, J. (2009). Representation of transport: A rural destination analysis. Annals of Tourism Research, 36(1), 103-123. 
Draper, S., Goodman, J., Hardyment, R. \& Murray, V. (2009). Tourism 2023. Four scenarios, a vision and a strategy for UK outbound travel and tourism. Forum for the Future. Online. Available (15/01/10) http://www.forumforthefuture.org/projects/traveland-tourism

Dredge, D. \& Jamal, T. (2015). Progress in tourism planning and policy: A post-structural perspective on knowledge production. Tourism Management, 51, 285-297.

Dunlap, R. E. \& van Liere, K. D. (1978). The "new environmental paradigm": A proposed instrument and preliminary results. Journal of Environmental Education, 9, 10-19.

Ernst-Vintila, A., Delouvée, S., \& Roland-Lévy, C. (2011). Under threat. Lay thinking about terrorism and the three-dimensional model of personal involvement: a social psychological analysis. Journal of Risk Research, 14(3), 297-324.

Festinger, L. (1957). A theory of cognitive dissonance. Stanford, CA: Stanford University Press.

Fischer, A., Peters, V., Neebe, M., Vavra, J., Kriel, A., Lapka, M., \& Megyesi, B. (2012). Climate Change? No, wise resource use is the issue: social representations of energy, climate change and the future. Environmental Policy and Governance, 22, 161-176.

Gangl, K., Kastlunger, B., Kirchler, E., \& Voracek, M. (2012). Confidence in the economy in times of crisis: Social representations of experts and laypeople. The Journal of SocioEconomics, 41, 603-614.

Gorge, H., Herbert, M., Özçağlar-Toulouse, N. \& Robert, I. (2015). What Do We Really Need? Questioning Consumption Through Sufficiency. Journal of Macromarketing, 35(1), 11-22. 
Gössling, S., Hall, C.M., Peeters, P. \& Scott, D. (2010). The Future of Tourism: Can Tourism Growth and Climate Policy be Reconciled? A Mitigation Perspective. Tourism Recreation Research, 35(2), 119-130.

Goulden, M., Ryley, T. \& Dingwall, R. (2014). Beyond 'predict and provide’: UK transport, the growth paradigm and climate change. Transport Policy, 32 (2014) 139-147.

Hall, C.M. (2013). Framing behavioural approaches to understanding and governing sustainable tourism consumption: beyond neoliberalism, “nudging” and "green growth”? Journal of Sustainable Tourism, 21(7), 1091-1109.

Heinberg, R. (2011). The End of Growth: Adapting to our new economic reality. Gabriola Island: New Society Publishers.

Higgins-Desbiolles, F. (2010). The elusiveness of sustainability in tourism: The cultureideology of consumerism and its implications. Tourism and Hospitality Research, 10(2), 116-129

Higham, J.E.S., Cohen, S.A. \& Cavaliere, C.T. (2014). Climate change, discretionary air travel and the 'flyers' dilemma'. Journal of Travel Research, 53(4), 462-475.

Hinch, T. (2008). Indigenous People and Tourism. Chapter 20, pp246-257. In Alan A. Lew, C. Michael Hall, Allan M. Williams (eds). A companion to tourism. John Wiley \& Sons.

Huesemann, M. \& Huesemann, J. (2011). Techno-fix: why technology won't save us or the environment. Gabriola, B.C.: New Society, 2011. 
Jovchelovitch, S. (2002). Re-thinking the diversity of knowledge: cognitive polyphasia, belief and representation. Psychologie et Société, 5(1), 121-138.

Joffe, H. (2003). Risk: from perception to social representation. British Journal of Social Psychology, 42, 55-73.

Kilbourne, W.E (2009). Sustainable communication and the Dominant Social Paradigm: Can the be integrated? Marketing Theory, 4, 187-208.

Kilbourne, W.E. \& Polonsky, M.J. (2009). Environmental attitudes and their relation to the Dominant Social Paradigm among University students in New Zealand and Australia. Australasian Marketing Journal, 13(2), 37-48.

Kilbourne, W.E., Beckmann, S.X. \& Thelen, E. (2002). The role of the dominant social paradigm in environmental attitudes. A multinational examination. Journal of Business Research, 55, 193-204.

Kuhn T. S. (1970). The Structure of Scientific Revolutions. Chicago: Chicago University Press.

Law, A., De Lacy, T., Lipman, G. \& Jiang, M. (2015). Transitioning to a green economy: the case of tourism in Bali. Journal of Cleaner Production, 111(Part B), 295-305.

Meadows, D., Randers, J., Meadows, D. \& Behrens, W.H. (1974). The Limits to Growth: A Report for the Club of Rome's Project on the Predicament of Mankind. $2^{\text {nd }}$ edition. New York: Universe Books.

Milbrath, L. (1984). Environmentalists: Vanguard for a New Society. Albany, NY: State University of New York Press. 
Miller, G., Rathouse, K., Scarles, C., Holmes, K. \& Tribe, J. (2010). Public understanding of sustainable tourism. Annals of Tourism Research, 37(3), 627-645.

Moloney, G., Z. Leviston, T. Lynam, J. Price, S. Stone-Jovicich, and D. Blair. 2014. Using social representations theory to make sense of climate change: what scientists and nonscientists in Australia think. Ecology and Society, 19(3), 19.

Moscovici, S. (1976). La Psychanalyse, son image, son public. (Psychoanalysis: its image, its public) Paris: PUF.

Moscovici; S. (1980). Toward a theory of conversion behavior. In L. Berkowitz (ed.); Advances in experimental social psychology (Vol. 13; pp. 209-239). New York: Academic Press.

Nyberg, D. \& Wright, C. (2015) Performative and Political: Corproate Constructions of Climate Change Risks. Organization. DOI 10.1177/1350508415572038

Olsen, M.E., Lodwick, D.G. \& Dunlap, R.E. (1992). Viewing the World Ecologically. Boulder, CO: Westview Press.

O’Neill, S. (2013). Image matters: Climate change imagery in the US, UK and Australian newspapers. Geoforum, 49 (2013) 10-19.

Parker, C., Letelier, M. \& Munoz, J. (2013). Elites, climate change and agency in a developing society: the Chilean case. Environment, Development \& Sustainability, 15, 1337-1363.

Pirages, D.C. \& Ehrlich, P.R. (1974). Ark ii: Social response to environmental imperatives. Freeman: San Francisco. 
Saldana, J. (2013). The Coding Manual for Qualitative Researchers (Vol. 2). London: Sage.

Sarrica, M. \& Wachelke, J. (2010). Peace and War as Social Representations: A Structural Exploration with Italian Adolescents. Universitas Psychologica, 9(2), 315-330.

Schirmeister, M. (2014). Controversial futures - discourse analysis on utilizing the "fracking" technology in Germany. European Journal of Futures Research. DOI 10.1007/s40309014-0038-5

Stern, N. (2006). Stern Review on the economics of Climate Change. HM Treasury. Available (14/11/06) http://www.hmtreasury.gov.uk/independent_reviews/stern_review_economics_climate_change/sternre view_index.cfm

Tsoukalas, I. (2006). A Method for Studying Social Representations. Quality \& Quantity, 40, 959-981.

United Nations Environment Programme and World Tourism Organisation (2012). Tourism in the Green Economy - Background Report. Madrid: UNWTO.

United Nations World Tourism Organisation (UNWTO) (2014). World Tourism Barometer. Volume 12. Retrieved (20/01/14) from http://mkt.unwto.org/en/barometer

Vergès, P. (1992). L’évocation de l'argent: Une méthode pour la définition du noyau central d'une représentation [Let's talk about money: A method aiming to identify the central core of a social representation]. Bulletin de Psychologie, 405, 203-9.

Vogel, R. (2009). Paradigm shifts as ideological changes: A Kuhnian view of endogenous institutional disruption. Research in the Sociology of Organisations, 27, 85-113. 
Wagner, W. \& Hayes, N. (2005). Everyday Discourse and Common-Sense: The Theory of Social Representation. New York: Palgrave Macmillan.

Wagner, W., Valencia, J., \& Elejabarrieta, F. (1996). Relevance, discourse and the "hot" stable core of social representations. A structural analysis of word associations. British Journal of Social Psychology. 35, 331-352.

Williams, A. \& Baláž, V. (2015). Tourism risk and uncertainty: theoretical reflections. Journal of Travel Research, 54(3), 271-287.

World Economic Forum (2009). Towards a Low Carbon Travel \& Tourism Sector. Aviation, Travel \& Tourism Partnership Programme. Available (13/07/15) http://www.unwto.org/media/news/en/pdf/LowCarbonTravelTourism.pdf

World Travel and Tourism Council (2016). Connecting Global Climate Action. Available (25/01/16) http://www.wttc.org/research/policy-research/travel-and-tourism-2015connecting-global-climate-action/

Young, M., Markham, F., Reis, A.C. \& Higham, J.E.S. (2015). Flights of fantasy: A reformulation of the flyers' dilemma. Annals of Tourism Research, 54, 1-15.

Zalik, A. (2010). Oil 'futures’: Shell’s scenarios and the social construction of the global oil market. Geoforum, 41(4), 553-564. 


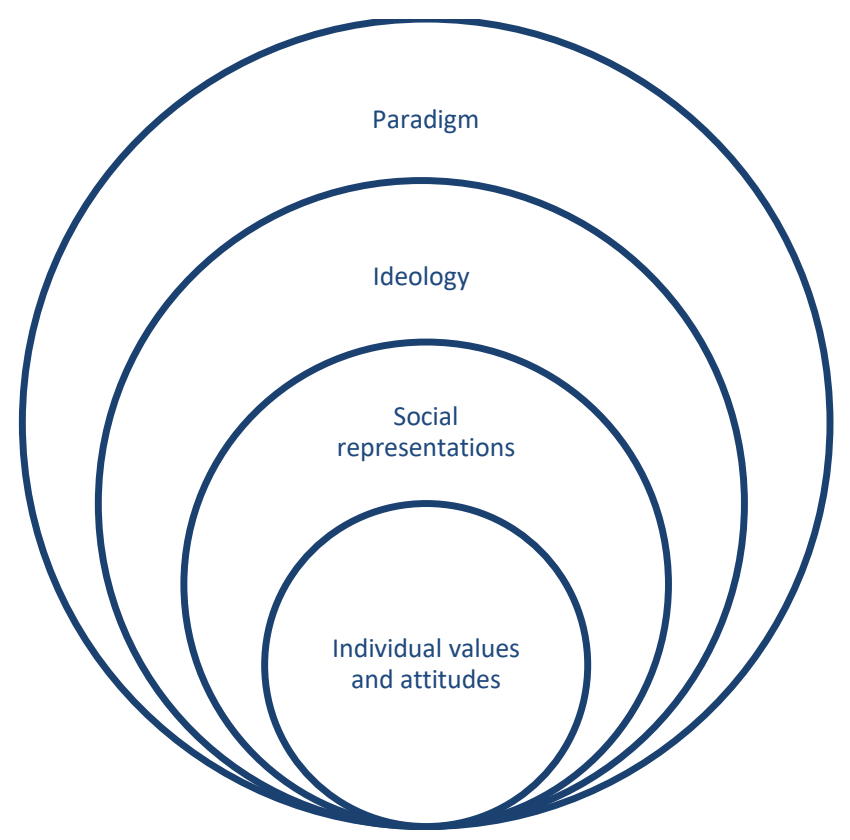

Figure 1 Conceptual model of social representations and their anchoring in ideologies and paradigms.

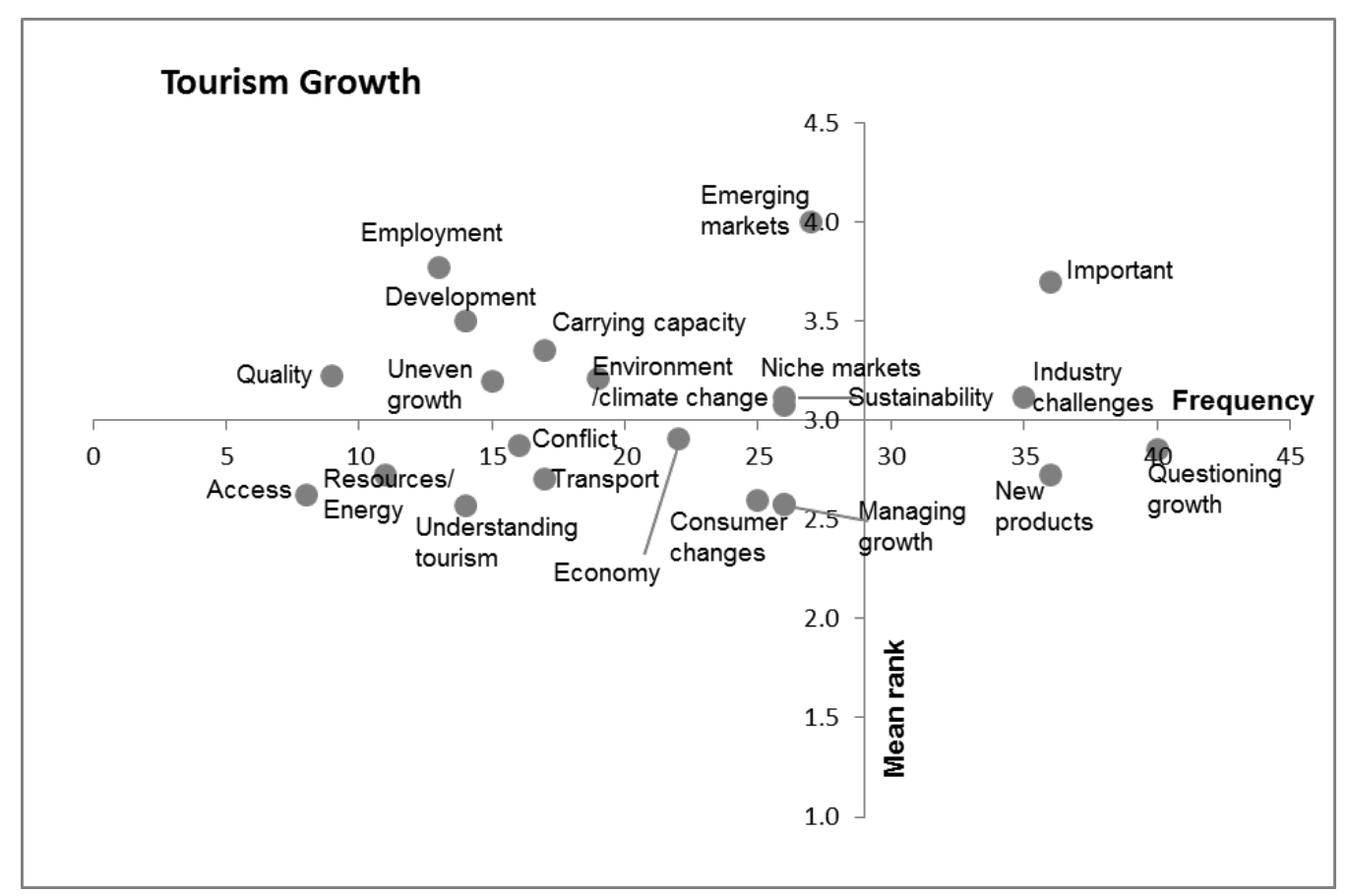

Figure 2 Frequency-ranking matrix for tourism experts' coded associations with the term 'tourism growth' $(\mathrm{N}=477)$. 


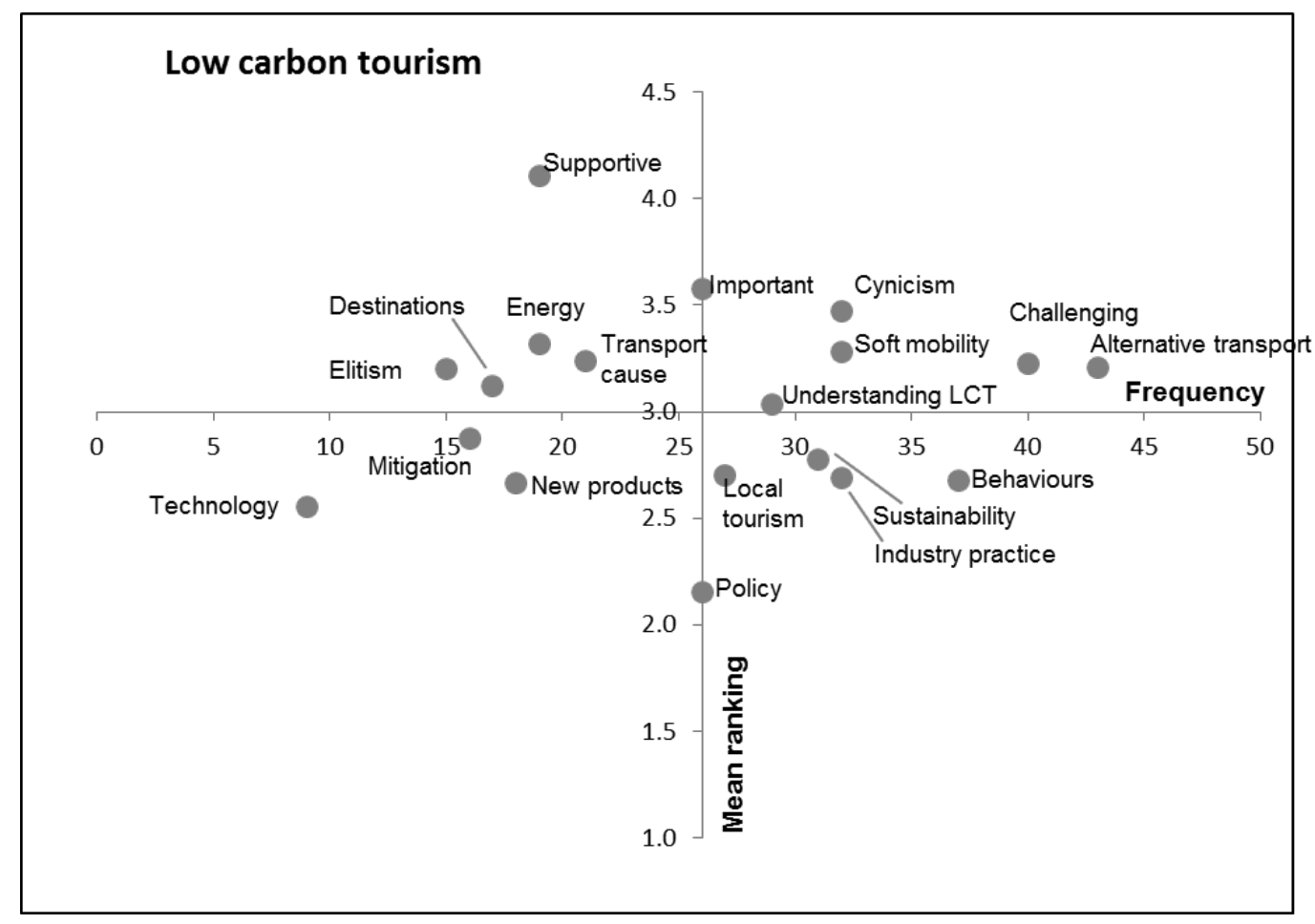

Figure 3 Frequency-ranking matrix for tourism experts' coded associations with the term 'low-carbon tourism' $(\mathrm{N}=486)$.

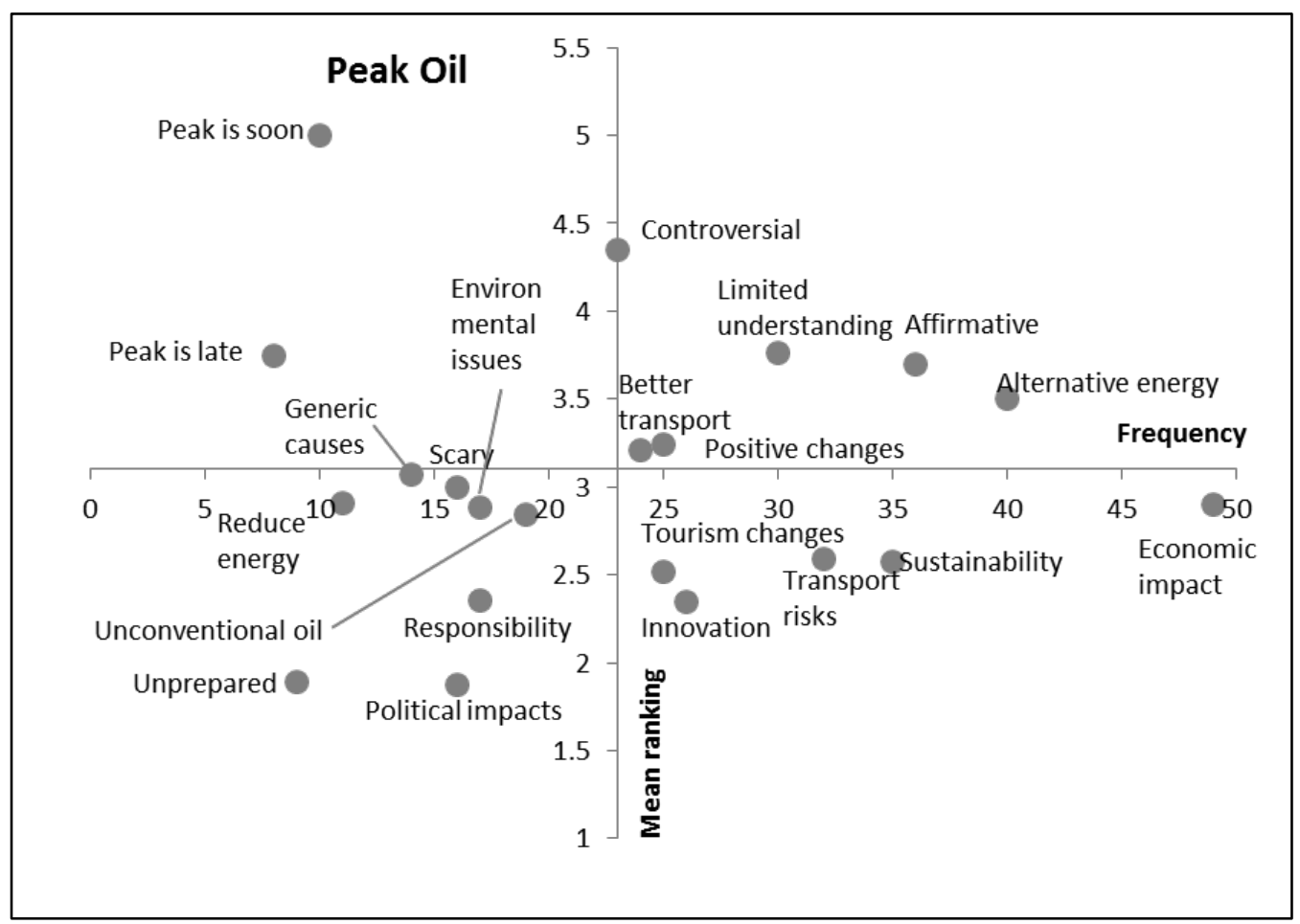

Figure 4 Frequency-ranking matrix for tourism experts' coded associations with the term 'peak oil' (N480). 


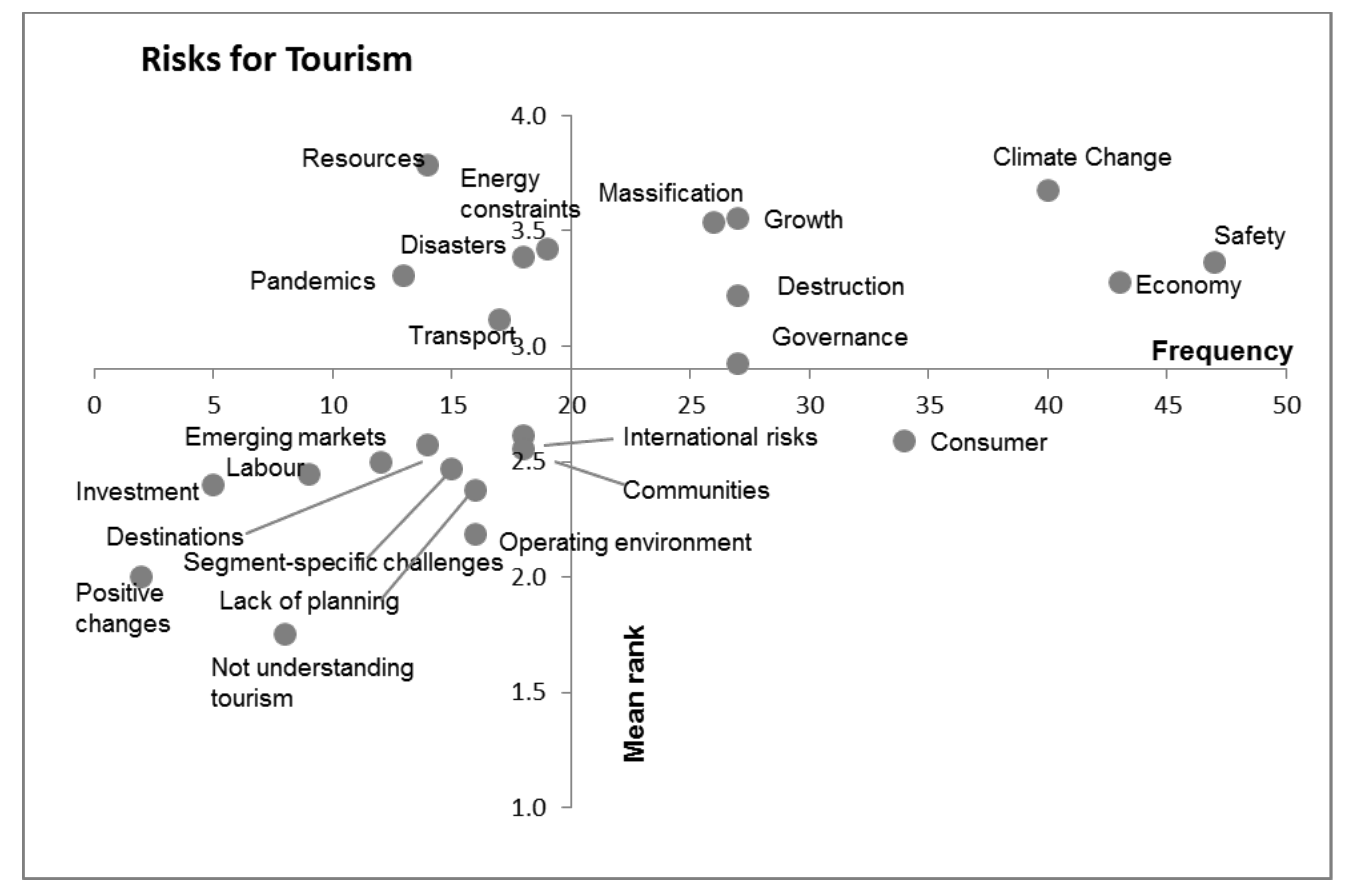

Figure 5 Frequency-ranking matrix for tourism experts' coded associations with the term 'future risks for tourism' $(\mathrm{N}=485)$.

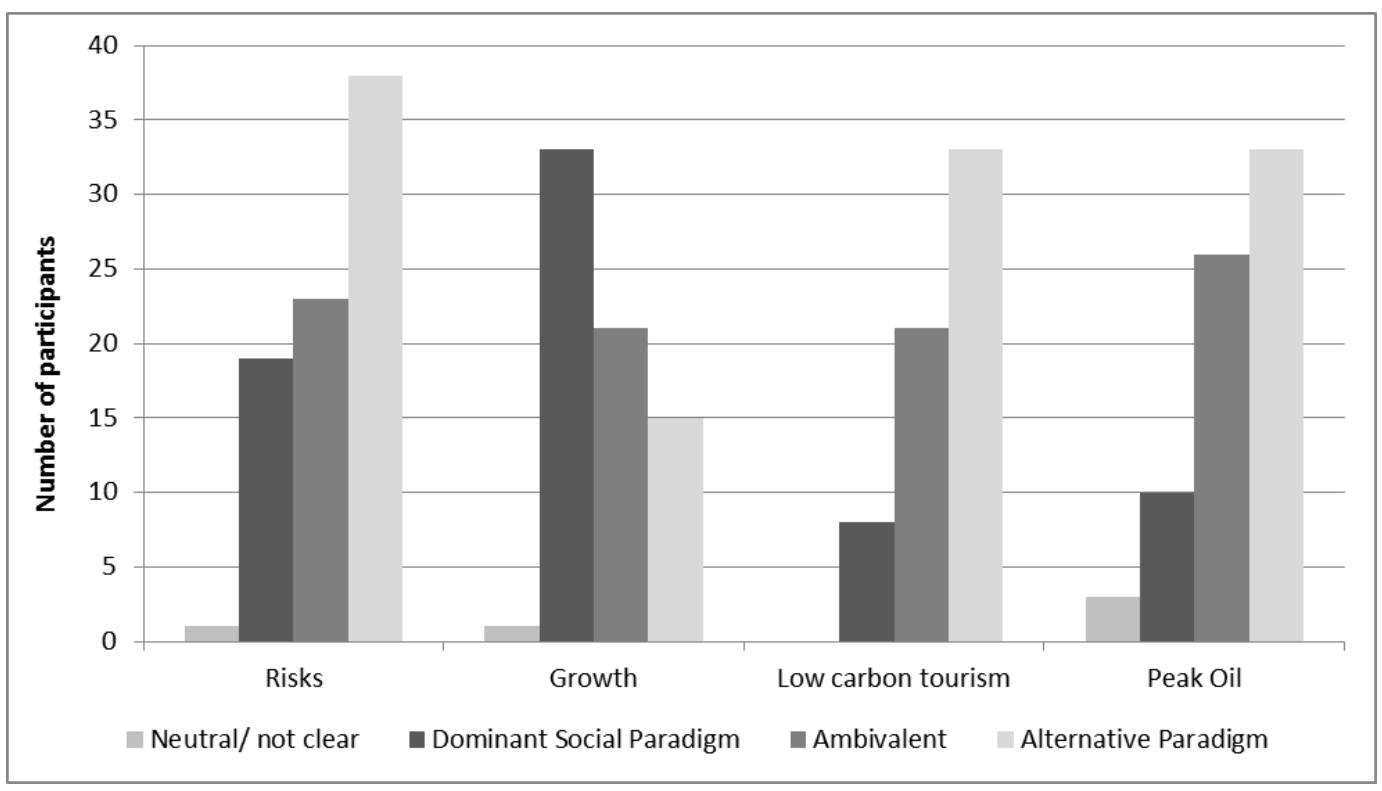

Figure 6 Tourism experts’ associations coded into underlying paradigms. 
Table 1 Sample characteristics $(\mathrm{N}=101)$

\begin{tabular}{ll}
\hline Variable & Percentage \\
\hline Gender & Male $70 \%$ \\
Region of residence & Female $30 \%$ \\
& United Kingdom 40\% \\
& Australia/New Zealand 30\% \\
& Europe 16\% \\
Age group & Other World 12\% \\
& $30-39$ years 13\% \\
& $40-49$ years 45\% \\
& $50-59$ years 36\% \\
Profession & Over 60 years 4\% \\
& Industry 37\% \\
& Academia 26\% \\
& Government 21\% \\
& Consulting and Not-for-Profit 14\% \\
\hline
\end{tabular}


Table 2 Comparison of key social representation codes for the four phenomena that refer to dimensions of the DSP

\begin{tabular}{|c|c|c|c|c|}
\hline & Tourism growth & Low carbon & Peak oil & Risks for tourism \\
\hline \multirow[t]{6}{*}{ Economic Growth } & Economy (global) & & Economic impacts & Economy (global) \\
\hline & Development & & & Massification \\
\hline & Uneven growth & Elitism (inequality) & & Lack of investment \\
\hline & Confirming growth & & & \\
\hline & Questioning growth & & & \\
\hline & Employment \& Money & & & Labour shortage \\
\hline \multirow{3}{*}{$\begin{array}{l}\text { Resource } \\
\text { abundance }\end{array}$} & Energy challenges & Energy sources & Alternative energy & Energy constraints \\
\hline & Carrying capacity & & Unconventional fuel & Limited resources \\
\hline & & & Reduce energy use & \\
\hline \multirow[t]{2}{*}{ Technology } & Transport modes and systems & Transport alternatives & Better transport options & \\
\hline & & Technological innovation & Innovation & \\
\hline \multirow[t]{4}{*}{ Politics } & $\begin{array}{l}\text { Understanding tourism (e.g. } \\
\text { research driven) }\end{array}$ & & & $\begin{array}{l}\text { Not understanding tourism } \\
\text { (underestimate importance) }\end{array}$ \\
\hline & Managing growth and policy & Policy and planning & Who is responsible & Insufficient planning \\
\hline & & $\begin{array}{l}\text { Climate change mitigation } \\
\text { policies (e.g. carbon tax) }\end{array}$ & Unprepared for peak oil & $\begin{array}{l}\text { Governance and politics } \\
\text { (good policies and } \\
\text { collaboration) }\end{array}$ \\
\hline & Conflict and equity & & Political impacts (e.g. war) & Community conflict \\
\hline
\end{tabular}

